\title{
THE INTERCHROMOSOME DISTRIBUTION OF CHIASMATA IN INTERCHANGE HETEROZYGOTES OF DELPHINIUM
}

\author{
S. L. BASAK and H. K. JAIN \\ Indian Agricultural Research Institute, New Delhi
}

Received I 2.vii.63

\section{INTRODUCTION}

INTERCHROMOSOMAL effects characterising chiasma formation have been reported in a number of organisms but, in general, these have been found to be so variable both at inter- and intraspecies levels that their significance has not been fully understood (Mather, I936; Rowlands, 1958). More recently, however, an organism has been found in which the interchromosome distribution of chiasmata consistently shows a particular trend. Two large and six small pairs of chromosomes can be readily identified in Delphinium ajacis and it has been shown following analysis on more than 30 plants that these two groups almost invariably show negatively correlated chiasma frequencies (Jain and Maherchandani, 1961; Basak and Jain, 1962). The present paper extends analysis of this type to a number of interchange heterozygotes of this species, in which it was found possible to separate the chromosomes into 2, 3 or 4 distinct groups, different from the two groups which can be recognised in the structurally homozygous control plants. This different grouping of chromosomes in the structural heterozygotes made it possible to determine if negatively correlated chiasma formation was characteristic for the large and small pairs of chromosomes, or whether interchromosome effects of this type occur irrespective of the size and number of chromosomes in the different groups.

\section{MATERIAL}

Delphinium ajacis (var. Comet) shows a diploid number of 16 chromosomes with two of the pairs considerably larger than others, so that two groups of chromosomes can be readily recognised even in normal plants. The structurally heterozygous plants were obtained by irradiating dry seeds at an intensity of $2400 \mathrm{r}$ per minute, with X-ray doses of 10,000 and I5,000 r. It was found possible to classify the heterozygotes on the basis of the number of distinct groups into which their chromosomes could be identified at metaphase- $I$; this number varying depending on the number of interchanges present and the particular pairs involved in them. Thus, 4 distinct groups were recognised in some of the heterozygotes in which two separate interchanges were present, one of these involving two of the small chromosome pairs, the other involving one large and one small pair. Two different multiples were formed in such plants, which by virtue of their size difference, could be readily identified (fig. I). The remaining three small chromosome pairs and the single large pair not involved in any of the structural changes provided the third and fourth identifiable groups of chromosomes.

The second class of interchanges heterozygotes showing three identifiable groups of chromosomes were characterised by a single reciprocal translocation involving 
one of the large and one of the small pairs. The three distinct groups in these plants were, thus, constituted of the single interchange multiple, the five small pairs and the single large pair (fig. 2). The third category of heterozygotes enabled separation of their chromosomes in only two groups as in the normal plants, but these were differently constituted. Two independent interchanges were detected in these plants, both involving one of the larger and one of the smaller chromosome pairs. The two multiples of four chromosomes, indistinguishable from one another, thus constituted one group, the four small pairs constituting the other (fig. 3). The fourth and the last class of heterozygotes also showed only two distinct groups of chromosomes which, however, were different from the corresponding two groups in the third category of heterozygotes described above. These plants showed an interchange between the two large pairs, so that a multiple constituted of the four large chromosomes, and six small bivalents were present (fig. 4). These heterozygotes differ from the normal plants in that while the four large chromosomes occur as two distinct bivalents in the latter plants, they form a single association in the former.

\section{METHOD}

The cytological technique employed for the fixation and staining of pollen mother cells and for the scoring of chiasmata has been described earlier (Jain and Maherchandani, 196I). On the basis of the earlier analysis and various theoretical considerations, it was concluded that the scoring of chiasmata at metaphase in this plant gives results on interchromosome distribution of chiasmata which are not significantly different from those at the earlier stages of prophase.

In order to find out whether the different groups of chromosomes showed chiasma formation in an independent or interrelated manner, the analysis of variance described fully by Elliot (1958) has been performed. This analysis makes it possible to divide the total variation with regard to chiasma distribution into three components-two of which are the internuclear variance which measure the variation in the total number of chiasmata among the pollen mother cells of a plant, and the inherent variance which gives a measure of the variation in the distribution of chiasmata between groups of chromosomes within nuclei. The relative magnitudes of these two variances indicate the direction and the degree of interchromosome correlation; a greater

TABLE I

\begin{tabular}{|c|c|c|c|}
\hline \multirow[b]{2}{*}{ Source of variation } & \multicolumn{3}{|c|}{ Degrees of freedom } \\
\hline & $\begin{array}{l}2 \text { intranuclear } \\
\text { groups of } \\
\text { chromosomes }\end{array}$ & $\begin{array}{l}3 \text { intranuclear } \\
\text { groups of } \\
\text { chromosomes }\end{array}$ & $\begin{array}{l}4 \text { intranuclear } \\
\text { groups of } \\
\text { chromosomes }\end{array}$ \\
\hline $\begin{array}{l}\text { Between nuclei (Internuclear) } \\
\text { Between groups of chromosomes } \\
\text { Inherent (between groups within } \\
\text { nuclei) }\end{array}$ & $\begin{array}{c}n-1 \\
1 \\
1(n-1)\end{array}$ & $\begin{array}{c}n-1 \\
2 \\
2(n-1)\end{array}$ & $\begin{array}{c}n-1 \\
3 \\
3(n-1)\end{array}$ \\
\hline Total & $2 n-1$ & $3^{n-1}$ & $4^{n-1}$ \\
\hline
\end{tabular}


inherent variance indicating a negative correlation, while a positive correlation is shown when the internuclear variance exceeds the inherent. The components of variation for the different classes of heterozygotes can be depicted as shown in table $\mathrm{I}$.

The inherent variance for the purpose of present analysis has been redesignated as intranuclear variance.

\section{RESULTS}

(i) Mean chiasma frequencies and variance ratios

The observations on mean chiasma frequencies and the estimates of internuclear and intranuclear variances for the various interchange

TABLE 2

Mean chiasma frequencies and inter and intranuclear variances

\begin{tabular}{|c|c|c|c|c|c|}
\hline $\begin{array}{c}\text { Plant } \\
\text { (code no.) }\end{array}$ & $\begin{array}{l}\text { No, of } \\
\text { cells }\end{array}$ & $\begin{array}{l}\text { Mean Xta } \\
\text { per cell }\end{array}$ & $\begin{array}{c}\text { Intranuclear } \\
\text { chromosome } \\
\text { groups } \dagger\end{array}$ & $\begin{array}{l}\text { Internuclear } \\
\text { variance }\end{array}$ & $\begin{array}{l}\text { Intranuclear } \\
\text { variance }\end{array}$ \\
\hline $\begin{array}{l}\mathrm{L}_{3} \mathrm{P}_{3} \\
\mathrm{R}_{3} \mathrm{P}_{15} \\
\mathrm{~L}_{12} \mathrm{P}_{5} \\
\mathrm{~L}_{52} \mathrm{P}_{1} \\
\mathrm{~L}_{4} \mathrm{P}_{9} \\
\mathrm{~L}_{14} \mathrm{P}_{3} \\
\mathrm{~L}_{13} \mathrm{P}_{9} \\
\mathrm{~L}_{1} \mathrm{P}_{2} \\
\mathrm{~L}_{83} \mathrm{P}_{1} \\
\mathrm{~L}_{13} \mathrm{P}_{10} \\
\mathrm{~L}_{84} \mathrm{P}_{2} \\
\mathrm{R}_{2} \mathrm{P}_{8} \\
\mathrm{~L}_{82} \mathrm{P}_{10} \\
\mathrm{~L}_{82} \mathrm{P}_{8} \\
\mathrm{~L}_{81} \mathrm{P}_{13} \\
\mathrm{~L}_{81} \mathrm{P}_{2} \\
\mathrm{TR}_{9} \mathrm{P}_{4} \\
\mathrm{~L}_{83} \mathrm{P}_{11} \\
\mathrm{~L}_{81} \mathrm{P}_{6} \\
\mathrm{~L}_{81} \mathrm{P}_{3}\end{array}$ & $\begin{array}{r}95 \\
\text { I } 50 \\
6 \mathrm{I} \\
76 \\
97 \\
59 \\
6 \mathrm{I} \\
5 \mathrm{I} \\
\mathrm{I} 25 \\
59 \\
88 \\
98 \\
63 \\
71 \\
55 \\
62 \\
98 \\
78 \\
76 \\
78\end{array}$ & 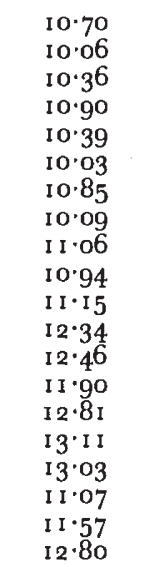 & $\begin{array}{c}2 \text { (class } 4) \\
2 \text { (class } 3 \text { ) } \\
3 \text { (class } 2) \\
, " \\
, " \\
, " \\
, " \\
, " \\
, " \\
, " \\
, " \\
\text { ", } \\
4 \text { (class I) } \\
\text {," }\end{array}$ & $\begin{array}{l}0.1 \text { I I } \\
0.1 \text { I } 6 \\
0.183 \\
0.220 \\
0.108 \\
0.185 \\
0.174 \\
0.09 \text { I } \\
0.130 \\
0.174 \\
0.140 \\
0.260 \\
0.285 \\
0.214 \\
0.278 \\
0.234 \\
0.166 \\
0.200 \\
0.194 \\
0.227\end{array}$ & $\begin{array}{l}0.314^{* *} \\
0.195^{* *} \\
0.33^{* *} \\
0.249 \\
0.22^{* *} \\
0.299^{* *} \\
0.233 \\
0.1 \mathrm{I} \\
0.26 \mathrm{I} * * \\
0.246^{*} \\
0.28 \mathrm{I} \\
0.374^{*} \\
0.522^{* *} \\
0.365^{* *} \\
0.399^{*} \\
0.633^{* *} \\
0.314^{* *} \\
0.302^{*} \\
0.297^{*} \\
0.423^{* *}\end{array}$ \\
\hline
\end{tabular}

** Significantly greater at I per cent. level.

* Significantly greater at 5 per cent. level.

$\uparrow$ See " Material" for fuller explanation.

heterozygotes are presented in table 2. It will be seen that the intranuclear variance in every case exceeds the internuclear variance. A statistical analysis shows the difference to be significant in $I 7$ of the 20 heterozygotes and it can, thus, be concluded that a negative correlation for chiasma formation is of general occurrence in these plants. This finding clearly shows that correlated formation of chiasmata in Delphinium is not restricted to that between the two groups of large and small chromosomes as observed earlier in the case of normal plants, but occurs within as well as between size classes. 
It will also be seen from table 2 that the different plants show negatively correlated chiasma formation in spite of considerable differences in their mean chiasma frequencies. These interplant differences in the number of chiasmata have been statistically tested

TABLE 3

Interplant variation in mean chiasma frequency

\begin{tabular}{|c|r|r|c|}
\hline Source of variation & D.f. & M.S. & F \\
\cline { 2 - 4 } Between plants . & 19 & $219 \cdot 59^{8}$ & $158 \cdot 554^{* *}$ \\
$\begin{array}{c}\text { Within plants } \\
\text { (Between cells) }\end{array}$ & $160:$ & $1 \cdot 385$ & \\
\hline
\end{tabular}

** Significant at $\mathrm{I}$ per cent. level.

TABLE 4

Test of heterogeneity of variances in table $I$

\begin{tabular}{|c|c|c|c|c|c|}
\hline \multicolumn{2}{|c|}{ Internuclear variance } & \multicolumn{3}{|c|}{ Intranuclear variance } \\
\hline Heterogeneity $\chi^{2}$ & D.f. & P & Heterogeneity $\chi^{2}$ & D.f. & P \\
\hline 97.644 & 19 & $<0.001$ & 160.523 & 19 & $<0.001$ \\
\hline
\end{tabular}

and found to be significant (table 3). The internuclear and intranuclear variances for different plants have also been analysed for their homogeneity as shown in table 4. It is found that for both variances, the different plants show significant heterogeneity.

\section{(ii) Intraplant analysis}

Following the evidence on negative interchromosome correlations and interplant heterogeneity of variances, the different plants were subjected to an intraplant analysis to determine whether a relationship exists between the number of chiasmata in particular groups of cells and the strength of the negative correlation observed in them. For this purpose, the different pollen mother cells in a plant, were divided into a number of groups by placing together all those which show the same number of chiasmata. The various intraplant cell groups have been made, in this way, to exhibit no internuclear variance, and their intranuclear variances given in table 5 can be taken as providing a direct measure of the magnitude of the negative correlation. The different heterozygotes in this table have been arranged into a number of groups not on the basis of their structural rearrangements, but primarily on considerations of the range of chiasma frequency shown 
by their pollen mother cells. One of the plants $\left(\mathbf{R}_{\mathbf{2}} \mathbf{P}_{6 a}\right)$ which could not be grouped with any of the others on this basis has been omitted from table 5, although in relation to the trend described below, it did not differ from the others.

It will be seen from the above table that there is a distinct tendency for the intranuclear variance to increase in the cell groups showing relatively high frequencies of chiasmata. That this increase is real

TABLE 5

Intraplant, intercell-group variation in intranuclear variance

\begin{tabular}{|c|c|c|c|c|c|c|c|}
\hline Plant No. & $\begin{array}{c}\text { Group I } \\
\left(9 X_{t a}\right)\end{array}$ & $\begin{array}{c}\text { Group } 2 \\
(10 \mathrm{Xta})\end{array}$ & $\begin{array}{l}\text { Group } 3 \\
\text { (II Xta) }\end{array}$ & $\begin{array}{l}\text { Group } 4 \\
(12 X \mathrm{X})\end{array}$ & $\begin{array}{l}\text { Group } 5 \\
(13 \mathrm{Xta})\end{array}$ & $\begin{array}{l}\text { Group } 6 \\
(14 \mathrm{Xta})\end{array}$ & $\begin{array}{l}\text { Group } 7 \\
\left({ }_{5} \mathrm{Xta}\right)\end{array}$ \\
\hline I $\left(L_{3} P_{3}\right)$ & 0.055 & 0.172 & 0.340 & 0.580 & $\ldots$ & $\ldots$ & $\ldots$ \\
\hline $2\left(\mathrm{R}_{3} \mathrm{P}_{15}\right)$ & 0.087 & 0.111 & 0.322 & 0.717 & $\ldots$ & $\ldots$ & $\ldots$ \\
\hline $3\left(\mathrm{~L}_{12} \mathrm{P}_{5}\right)$ & 0.075 & 0.103 & 0.183 & $\mathrm{I} \cdot 000$ & $\cdots$ & $\cdots$ & $\cdots$ \\
\hline $4\left(\mathrm{~L}_{4} \mathrm{P}_{8}\right)$ & o. IIo & $0 \cdot 190$ & 0.302 & $0 \cdot 368$ & $\cdots$ & $\cdots$ & $\cdots$ \\
\hline $5\left(\mathrm{~L}_{14} \mathrm{P}_{3}\right)$ & 0.237 & o.199 & 0.185 & 0.150 & $\ldots$ & $\cdots$ & $\cdots$ \\
\hline $6\left(\mathrm{~L}_{1} \mathrm{P}_{2}\right)$ & $0 \cdot 008$ & 0.134 & 0.066 & & $\cdots$ & $\cdots$ & $\cdots$ \\
\hline $7\left(\mathrm{~L}_{83} \mathrm{P}_{11}\right)$ & $0 \cdot 083$ & $0 \cdot 184$ & $0 \cdot 245$ & 0.097 & $\cdots$ & $\cdots$ & $\cdots$ \\
\hline I-7 (pooled) & $0 \cdot 110$ & $0 \cdot 160$ & $0 \cdot 259$ & 0.341 & $\ldots$ & $\cdots$ & $\cdots$ \\
\hline $8\left(\mathrm{~L}_{52} \mathrm{P}_{1}\right)$ & 0.092 & $0 \cdot 198$ & 0.292 & 0.435 & 0.588 & ... & $\cdots$ \\
\hline $9\left(\mathrm{~L}_{13} \mathrm{P}_{8}\right)$ & 0.112 & $0 \cdot 169$ & 0.245 & 0.259 & 0.385 & $\cdots$ & $\cdots$ \\
\hline $10\left(\mathrm{~L}_{83} \mathrm{P}_{1}\right)$ & $\cdots$ & 0.151 & $0.23^{\circ}$ & 0.308 & $0.3^{60}$ & $\cdots$ & $\cdots$ \\
\hline $11 \quad\left(\mathrm{~L}_{13} \mathrm{P}_{10}\right)$ & $\cdots$ & 0.130 & $0.24^{2}$ & 0.259 & 0.245 & $\cdots$ & $\cdots$ \\
\hline $12\left(\mathrm{~L}_{84} \mathrm{P}_{2}\right)$ & $\cdots$ & $0 \cdot 156$ & 0.227 & $0 \cdot 39^{6}$ & 0.202 & $\cdots$ & .. \\
\hline I3 $\left(L_{8}\right.$ & $\cdots$ & o'I59 & $0 \cdot 373$ & $0 \cdot 368$ & 0.217 & $\cdots$ & $\cdots$ \\
\hline 8-1 3 (pooled) & $0 \cdot 098$ & o. I 59 & $0 \cdot 278$ & $0.35 \mathrm{I}$ & $0 \cdot 3^{16}$ & ... & ... \\
\hline${ }_{14}\left(\mathrm{~L}_{82} \mathrm{P}_{10}\right)$ & $\ldots$ & $\cdots$ & 0.239 & 0.554 & 0.664 & 0.662 & $\cdots$ \\
\hline $15\left(L_{82} P_{8}\right)$ & $\ldots$ & $\ldots$ & 0.305 & 0.566 & 0.312 & 0.475 & \\
\hline $\mathrm{I} 6\left(\mathrm{~L}_{81} \mathrm{P}_{13}\right)$ & $\ldots$ & $\ldots$ & $0 \cdot 136$ & 0.316 & 0.403 & 0.500 & 0.860 \\
\hline${ }_{17}\left(\mathrm{~L}_{81} \mathrm{P}_{2}\right)$ & $\cdots$ & ... & $\cdots$ & 0.305 & 0.370 & 0.433 & $\cdots$ \\
\hline $18\left(\mathrm{TR}_{8} \mathrm{P}_{4}\right)$ & $\cdots$ & $\ldots$ & ... & 0.259 & $0 \cdot 353$ & 0.470 & $\ldots$ \\
\hline $19\left(\mathrm{~L}_{81} \mathrm{P}_{3}\right)$ & $\cdots$ & $\cdots$ & 0.254 & $0 \cdot 425$ & 0.472 & $0.44^{\circ}$ & 0.322 \\
\hline I 4-I9 (pooled) & ... & ... & 0.248 & 0.402 & 0.419 & $0 \cdot 483$ & 0.520 \\
\hline
\end{tabular}

and cannot be explained on a purely numerical basis is clear from the fact that the rise in the number of chiasmata is not expected to lead to as large variances as observed. The expected rate of increase in variance on a purely numerical basis, is the squared rate of increase in mean. To take an example, the expected intranuclear variance for the last cell group in the case of the first plant would be $12^{2} / 9^{2}$ times variance of group $\mathrm{r}$. The observed value of $0.5^{8}$ was nearly 5 times greater.

The above observations on a positive relationship between chiasma frequency and intranuclear variance are found to be largely confirmed by the statistical analysis presented in table 6 . The analysis shows that 
TABLE 6

Heterogeneity of intranuclear variances between groups in table 4

\begin{tabular}{|c|c|c|c|}
\hline $\begin{array}{l}\text { Pooled groups } \\
\text { of plants }\end{array}$ & $\chi^{2}$ & D.f. & $\mathbf{P}$ \\
\hline $\begin{array}{c}1-7 \\
8-13 \\
14-19\end{array}$ & $\begin{array}{l}59 \cdot 636 \\
43.924 \\
14.881\end{array}$ & $\begin{array}{l}3 \\
4 \\
4\end{array}$ & $\begin{array}{c}<0.001 \\
<0.001 \\
<0.01->0.001\end{array}$ \\
\hline
\end{tabular}

the increase in intranuclear variance with increasing chiasma frequencies in the higher cell groups is highly significant for each of the three pooled groups of heterozygotes. These pooled observations also

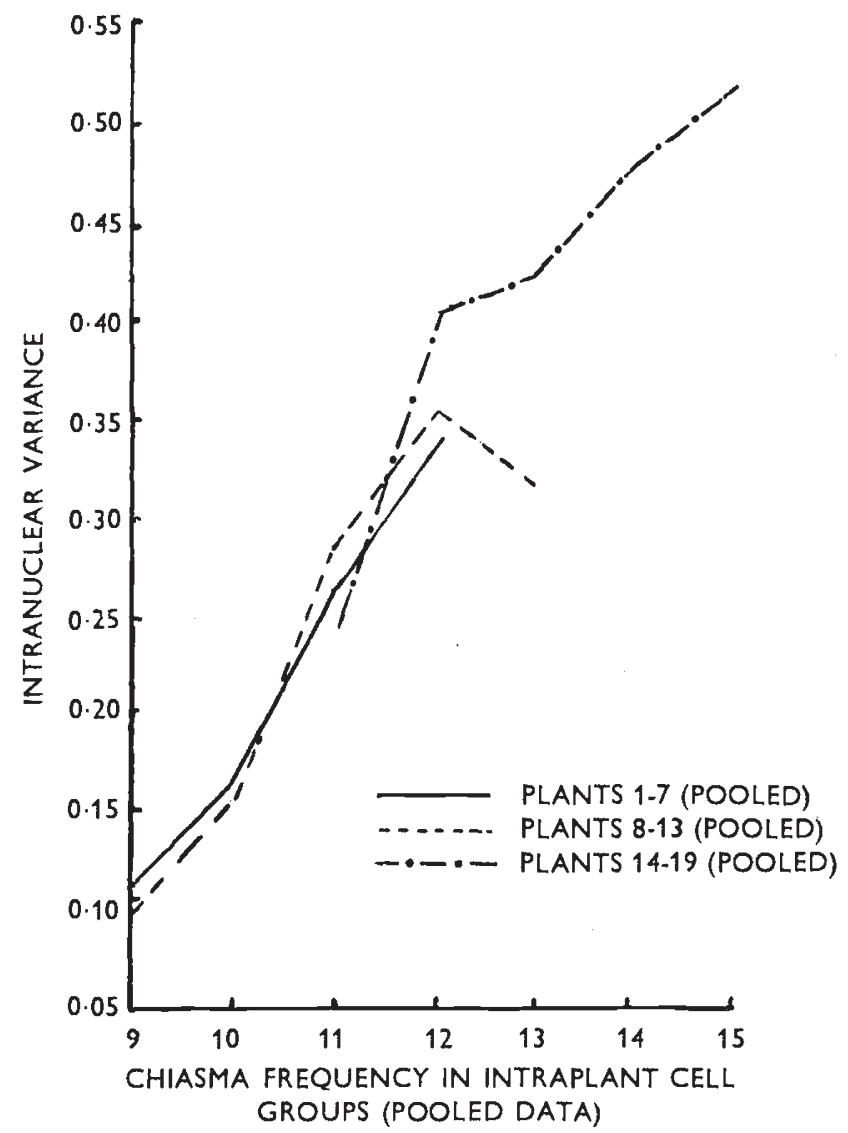

Frg. 5.-Diagram showing the variation in intranuclear variance with increased chiasma frequency in the cell groups.

presented diagrammatically (fig. 5) have greater reliability in view of their larger number of degrees of freedom. A large number of individual plants, however, (I4 out of I9) were also found to show heterogeneity of intranuclear variances for the different cell groups. 


\section{DISCUSSION}

The earlier analysis on structurally normal plants of Delphinium has shown that the two groups of large and small chromosomes show negatively correlated chiasma formation. The present analysis on the interchange heterozygotes, in which two, three or four groups of chromosomes, different from those in the normal plants could be recognised, supplements the earlier finding by showing that interrelated chiasma formation in this organism is not restricted to the two groups of large and small chromosomes but occurs more generally.

The intraplant analysis on the heterozygotes as on the homozygotes earlier, can be interpreted as indicating that the interchromosome effects characterising chiasma formation are relatively absent in cells with low chiasma frequency, but become more pronounced as the number rises beyond this low level, until a saturation point is reached. This would suggest that the chiasmata in a plant can be divided into two fractions, a first fraction which is distributed over all the chromosomes in an autonomous manner, and a second, in relation to which the different chromosome pairs show a competition affect. Although it has been generally supposed that the different chromosomes compete to have the chiasmata, the possibility cannot be ruled out that they " compete" not to have them. The effect on intranuclear variance would probably be of the same nature in either case.

A probable interpretation of the autonomous fraction is that it ensures a minimum number of chiasmata for each of the bivalents irrespective of their size differences. This minimum chiasma formation is obviously of great importance for the continued association of homologous chromosomes at metaphase-I and in this way for their disjunctional separation. However, facilitating the regular separation of homologous chromosomes does not appear to be the only function of chiasmata, as can be inferred from the observation that the bivalents quite commonly show several chiasmata and not only do we find variation in their number at interspecies level but also at the intraspecies level when differences of chromosome number and karotype are not involved. The partial chiasma-type hypothesis of Darlington (1937), which has received further support from a number of studies in recent years including one on the present species (Brown and Zohary, I955; Noda, I96o; Jain and Basak, I963) emphasises a more important role of the chiasmata. Since chiasmata on this interpretation constitute an important property of the genetic system of an organism, variation in their number appears to have been selected in response to the adaptive requirements of the populations (Stebbins, I958).

It may be asked at this stage what determines the relative magnitudes of the autonomous and the interrelated fractions on which depends the occurrence of interchromosomal effects. Chromosome length would appear to be an important factor. It may be supposed that the autonomous fraction would be greater in organisms with 
relatively large chromosomes, unless the chiasma frequency also rises proportionately. The symmetry of the karyotype is another factor which may determine the magnitude of the autonomous fraction. Where chiasma interference (as a rule) does not operate across the centromere, metacentric chromosomes are better fitted to have a minimum of 2 chiasmata than chromosome pairs of the same length having sub-terminal centromeres. Thus, a greater length of the chromosome escapes suppression in the more symmetrical types. It is interesting to consider these two factors in relation to the chromosomes of Delphinium. The karyotype in this organism is highly asymmetrical both in terms of size differences as well as the position of the centromeres (Levitsky, I93I). The small size of many of the chromosomes as well as the sub-terminal position of the centromere in them, can both be expected to reduce the autonomous fraction considerably, thus increasing the magnitude of the interrelated fraction. The Delphinium chromosomes, in this way, would appear to provide ideal conditions for the occurrence of inter-chromosomal effects. The fact that such effects are found to occur very consistently in this species, provides support for the postulated factors governing the distribution. It would obviously be of great interest to extend analysis on interchromosome distribution of chiasmata to organisms in which the karyotype is very different from that in Delphinium.

The above interpretation of the conditions which favour interchromosome effects in chiasma formation, may account for the variable behaviour in this regard to different species, but it fails to explain such differences at the intraspecies level when no differences of the karyotype are involved. That such variability exists has been pointed out earlier and is shown by the analysis of a number of authors including Rowlands (1958) and Elliot (1958). It is possible that variation in the autonomous fraction may be due to other undefined factors. To consider one such possible factor, chiasma interference may be more marked in one plant than in another, although no differences of the karyotype are involved. It is perhaps significant in this context that while some of the plants of Rowlands and Elliot showing relatively high chiasma frequency fail to show the expected interchromosome effects of the negative type, there is no evidence that plants with relatively low chiasma frequency unexpectedly show such effects. It would appear that while the autonomous fraction may be unexpectedly large in some cases, no such unexpected variation occurs in the lower direction. Such a variation, if it were to occur, would be even more difficult to explain.

\section{SUMMARY}

Interchromosome distribution of chiasmata has been studied in interchange heterozygotes of Delphinium, in which it was found possible to distinguish two or more groups of chromosomes on the basis of their size differences and meiotic configurations. It was found that there is 

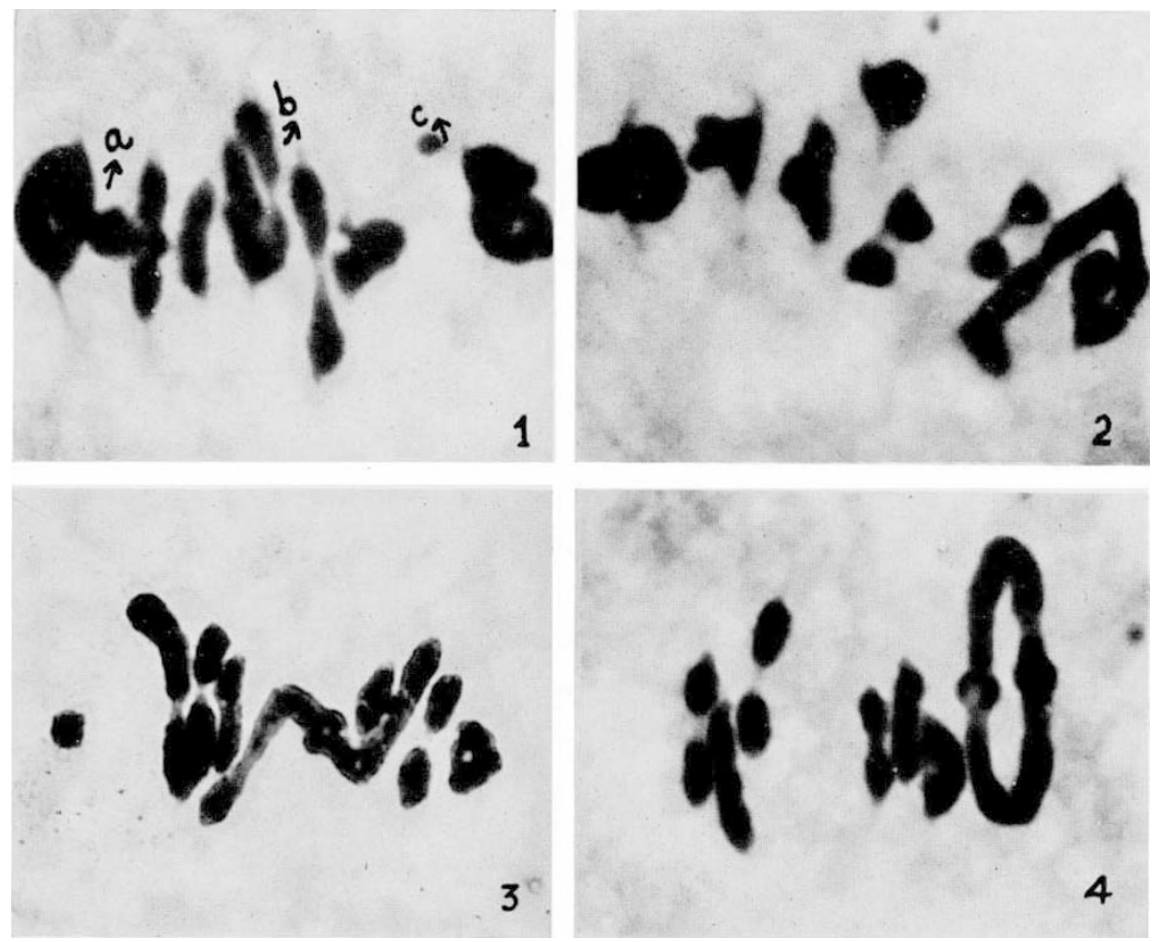

FIG. 1.-PMC showing two interchange multiples of four and three chromosomes, the first (marked $a$ ) involves one large and one small pair, the second $(b)$ two small pairs. The unpaired minute chromosome $(c)$ forms part of the second translocation complex. The single large bivalent and the three small bivalents not involved in structural changes provide two more recognisable groups. The cell shows a total of 14 chiasmata, 4 in the first interchange complex, 2 in the second, 3 in the large bivalent and 5 in the three small bivalents. $\times 2670$.

Frg. 2.-PMC showing an interchange multiple of four chromosomes, a single large bivalent and five small bivalents. The three groups show a total of 3,3 and 8 chiasmata respectively. $\times 3600$.

FIa. 3.-An interchange multiple of four chromosomes and a second multiple, which is identical except that one of its four chromosomes is detached, provide the first identifiable group in this cell. The second group is constituted by the four small bivalents. The two groups indicate a total of 5 and 6 chiasmata respectively. $\times 2430$.

FIG. 4.-PMC showing an interchange multiple of four chromosomes involving the two large pairs. The multiple has 4 chiasmata while the 6 small bivalents show a total of $7 \mathrm{Xta} . \times 3000$. 
negatively correlated formation of chiasmata between the different groups irrespective of the size of chromosomes included in them. An intraplant analysis showed that the chiasma frequency in these plants can be divided into an autonomous component which the different chromosome pairs claim independently of one another and a second fraction for which they indicate correlated distribution. It has been suggested on the basis of various considerations that the relative proportion of these two fractions may be determined in an important manner by the karyotype of the organism, particularly its symmetry. The consistent occurrence of interchromosomal effects in relation to chiasma formation in the case of Delphinium appears to be a function of the highly asymmetrical karyotype of this plant.

Acknowledgment.-We thank Dr B. P. Pal and Dr M. S. Swaminathan for their kind interest and encouragement.

\section{REFERENCES}

BASAK, S. L., AND JAIN, H. K. I962. Autonomous and interrelated formation of chiasmata in Delphinium chromosomes. Chromosoma, 13, 577-587.

BRown, s. W., AND zOHARY, D. I955. The relationship of chiasmata and crossing over in Lilium formosanum. Genetics, $40,850-873$.

Darlington, C. D. 1937. Recent Advances in Cytology, and ed. London: Churchill. ELLIOT, G. G. 1958. Environmental effects on the distribution of chiasmata among nuclei and bivalents and correlation between bivalents. Heredity, I2, 429-439. JAIN, H. K., AND BASAK, s. L. 1963. Genetic interpretation of chiasmata in Delphinium. Genetics, 48, 329-339.

JAIN, H. K., AND MAHERGHANDANI, N. I $96 \mathrm{I}$. The control of intranuclear distribution of chiasmata in Delphinium. Heredity, $16,383-392$.

Levitsky, G. A. I93I. The karyotype in systematics. Bull. Appl. Bot. Genet. Plant Breeding, 27, 220-240.

MATHER, K. 1936. Competition between bivalents during chiasma formation. P.R.S., B, I20, 208-227.

NODA, s. I96o. Chiasma studies in structural hybrids. II. Reciprocal translocation in Lilium maximowiezii. Cytologia, 25, 456-46o.

Rowlands, D. G. I958. The control of chiasma frequency in Vicia faba L. Chromosoma, 9, I $76-184$.

STEBBINS, G. L. 1958. Longevity, habitat and release of genetic variability in the higher plants. Cold Spring Harbour Symp. Quant. Biol., 23, 365-377. 